\title{
RAMSEY PROPERTIES OF RANDOM GRAPHS AND FOLKMAN NUMBERS
}

\author{
VOJTĚCH RÖDL ${ }^{1}$ \\ Emory University, Atlanta, USA \\ e-mail: rodl@mathcs.emory.edu \\ ANDRZEJ RuCińsKI ${ }^{2}$ \\ A. Mickiewicz University, Poznań, Poland \\ e-mail: rucinski@amu.edu.pl \\ AND \\ Mathias SCHACHT ${ }^{3}$ \\ Universität Hamburg, Hamburg, Germany \\ e-mail: schacht@math.uni-hamburg.de
}

\begin{abstract}
For two graphs, $G$ and $F$, and an integer $r \geq 2$ we write $G \rightarrow(F)_{r}$ if every $r$-coloring of the edges of $G$ results in a monochromatic copy of $F$. In 1995, the first two authors established a threshold edge probability for the Ramsey property $G(n, p) \rightarrow(F)_{r}$, where $G(n, p)$ is a random graph obtained by including each edge of the complete graph on $n$ vertices, independently, with probability $p$. The original proof was based on the regularity lemma of Szemerédi and this led to tower-type dependencies between the involved parameters. Here, for $r=2$, we provide a self-contained proof of a quantitative version of the Ramsey threshold theorem with only double exponential dependencies between the constants. As a corollary we obtain a double exponential upper bound on the 2-color Folkman numbers. By a different proof technique, a similar result was obtained independently by Conlon and Gowers.
\end{abstract}

Keywords: Ramsey property, random graph, Folkman number .

2010 Mathematics Subject Classification: 05C80, 05C55

\footnotetext{
${ }^{1}$ Research supported by NSF grant DMS 080070.

${ }^{2}$ Research supported by the Polish NSC grant 2014/15/B/ST1/01688. Part of research performed at Emory University, Atlanta.

${ }^{3}$ Research supported by the Heisenberg-Programme of the Deutsche Forschungsgemeinschaft.
} 


\section{REFERENCES}

[1] J. Balogh, R. Morris and W. Samotij, Independent sets in hypergraphs, J. Amer. Math. Soc. 28 (2015) 669-709.

doi:10.1090/S0894-0347-2014-00816-X

[2] D. Conlon and T. Gowers, An upper bound for Folkman numbers, preprint.

[3] E. Friedgut, V. Rödl and M. Schacht, Ramsey properties of random discrete structures, Random Structures Algorithms 37 (2010) 407-436. doi: $10.1002 /$ rsa. 20352

[4] S. Janson, T. Łuczak and A. Ruciński, Random Graphs (John Wiley and Sons, New York, 2000). doi: $10.1002 / 9781118032718$

[5] R. Nenadov and A. Steger, A short proof of the random Ramsey theorem, Combin. Probab. Comput. 25 (2016) 130-144. doi:10.1017/S0963548314000832

[6] V. Rödl and A. Ruciński, Threshold functions for Ramsey properties, J. Amer. Math. Soc. 84 (1995) 917-942. doi: $10.2307 / 2152833$

[7] V. Rödl, A. Ruciński and M. Schacht, Ramsey properties of random k-partite, $k$ uniform hypergraphs, SIAM J. Discrete Math. 21 (2007) 442-460. doi: $10.1137 / 060657492$

[8] V. Rödl, A. Ruciński and M. Schacht, An exponential-type upper bound for Folkman numbers, Combinatorica, in press. doi:10.1007/s00493-015-3298-1

[9] D. Saxton and A. Thomason, Hypergraph containers, Invent. Math. 201 (2015) 925-992. doi:10.1007/s00222-014-0562-8

[10] E. Szemerédi, Regular partitions of graphs, in: Problèmes Combinatoires et Théorie des Graphes (Colloq. Internat. CNRS, Univ. Orsay, Orsay, 1976), Colloq. Internat. CNRS 260 (CNRS, Paris, 1978) 399-401.

Received 11 September 2015

Revised 28 June 2016

Accepted 29 June 2016 